\title{
The role of malate in plant homeostasis
}

\author{
Iris Finkemeier and Lee J Sweetlove*
}

\author{
Address: University of Oxford, Department of Plant Sciences, South Parks Road, Oxford OX1 3RB, UK \\ *Corresponding author: Lee J Sweetlove (lee.sweetlove@plants.ox.ac.uk) \\ FI000 Biology Reports 2009, I:47 (doi: 10.34I0/BI-47) \\ The electronic version of this article is the complete one and can be found at: http://FI000.com/Reports/Biology/content/I/47
}

\begin{abstract}
Malate is a central metabolite of the plant cell with important roles in plant physiology and metabolism. Here, we summarize the most recent advances in our understanding of malate homeostasis in central metabolism, guard cell functioning, and root exudation.
\end{abstract}

\section{Introduction and context}

The dicarboxylic acid malate has a multitude of functions in plant metabolism and homeostasis. These range from its most prominent roles in the mitochondrial tricarboxylic acid (TCA) cycle and in CAM and C4 metabolism, to its roles as an osmoticum, as a regulator of $\mathrm{pH}$ homeostasis, as a reducing equivalent that is shuttled between subcellular compartments, and as an important root exudate [1]. Although the various functions of malate in plant metabolism have been known for many years, the recent identification of diverse malate transport proteins in various tissues and compartments and the analysis of mutant and transgenic plants with altered malate metabolism have shed new light on its broader importance for cellular functions.

\section{Major recent advances \\ Perturbation of malate metabolism in the TCA cycle has unexpected biochemical consequences}

As an intermediate of the TCA cycle, malate is intimately associated with mitochondrial energy metabolism and is also the origin of carbon skeletons exported from the mitochondrion in support of amino acid biosynthesis [2]. However, recent reverse genetic experiments targeting TCA cycle enzymes suggest that malate has a metabolic influence well beyond the standard textbook associations. In particular, antisense suppression of mitochondrial malate dehydrogenase in tomato plants leads to an unexpected increase in the rate of photosynthesis [3]. While the precise role of the TCA cycle in leaves is still the subject of debate [4], one nevertheless would anticipate that inhibition of TCA cycle flux would have a negative rather than a positive effect on photosynthesis. The mechanism for this effect is not due simply to inhibition of the TCA cycle; the suppression of other TCA cycle enzymes does not necessarily have the same consequence [5]. In addition, disruption of malate metabolism has a specific effect on root growth that is independent of alterations in leaf metabolism [6]. Again, the mechanism for this is not completely clear, but inhibition of root respiration and consequent changes in root metabolism, including altered giberellic acid levels, may be responsible. One aspect that may help explain the different biochemical phenotypes resulting from inhibition of different steps in the TCA cycle is the presence of different flux modes within the cycle $[7,8]$. Ultimately, detailed metabolic network flux analysis will be required to fully understand the manifold metabolic roles of malate.

\section{AtABCBI4 and SLACI regulate malate homeostasis involved in stomatal movement of guard cells}

The transport of malate across the plasma membrane of guard cells is an important process in the regulation of guard cell turgor pressure, mediating guard cell opening and closure. Stomata respond to changes in external $\mathrm{CO}_{2}$ concentrations, and increased apoplastic malate levels can be observed at high $\mathrm{CO}_{2}$ levels when stomata are closed [9]. Moreover, it has been demonstrated that the presence of floating leaves on a malate solution leads to stomatal closure $[9,10]$. Although the existence of a malate-sensitive guard cell anion channel was reported 
by Hedrich and Marten [11] more than 15 years ago, the identity of this channel was unknown until recently. A major breakthrough was the independent identification by two groups $[12,13]$ of the slow anion channelassociated 1 (SLAC1) protein, which possesses features of a C4-dicarboxylate transporter. This channel was shown to affect slow anion current channel function and thus malate ion homeostasis in guard cells. SLAC1 loss-offunction mutants showed a constitutive stomatal opening phenotype with a complete lack of high $\mathrm{CO}_{2}$-induced stomatal closure, and an overaccumulation of malate, fumarate, and potassium guard cell protoplasts was observed [12]. In addition, the first plasma membrane $\mathrm{ABC}$ transporter (AtABCB14) responsible for uptake of malate from the apoplast was identified recently [10]. Malate uptake into guard cells leads to stomatal opening through increased guard cell turgor. Hence, AtABCB14 knockout plants showed more pronounced stomatal closure at high $\mathrm{CO}_{2}$ concentrations, as the cells were still able to release malate but not to take it up again. In line with this, overexpressors of AtABCB14 showed a highly decreased stomatal closure response to high $\mathrm{CO}_{2}$. Thus, it was demonstrated that AtABCB14 plays an important role in the $\mathrm{CO}_{2}$-mediated guard cell response. Furthermore, transgenic tomato plants with suppressed expression of fumarase (the TCA cycle enzyme that produces malate) were also reported to have defects in stomatal opening leading to decreased photosynthetic rates and plant growth [14]. Interestingly, total levels of leaf malate were increased rather than decreased in these lines as one might expect. However, there may be guard cell-specific effects on malate homeostasis in the fumarase-deficient lines and these effects might be different from those seen in whole tissues.

\section{The molecular mechanisms that regulate malate exudation in roots conferring aluminium tolerance have been identified}

The excretion of organic acids, including malate, by plant roots is a key factor in the tolerance of plants toward aluminium $(\mathrm{Al})$ toxicity by chelation of $\mathrm{Al}$ in the soil (reviewed in [15]). Al toxicity is a problem that affects agricultural crop growth worldwide, and resolving the mechanism of Al tolerance in plants is of great economic importance. Arabidopsis plants, as well as wheat, excrete high levels of malate when the root is subjected to $\mathrm{Al}^{3+}$ stress, and the level of $\mathrm{Al}$ tolerance correlates with the amount of excreted malate in different ecotypes of these species [16,17]. Recently, the gene responsible for Alactivated malate efflux, ALMT1 (Al-activated malate transporter 1), was identified in wheat and Arabidopsis $[18,19]$ and the physiological properties of $\mathrm{Al}^{3+}$-activated malate transport were studied in Xenopus oocytes [20]. Moreover, overexpression of wheat ALMT1 in barley resulted in enhanced exudation of malate by roots following $\mathrm{Al}^{3+}$ treatment and increased $\mathrm{Al}$ tolerance of the normally Al-sensitive barley [21]. These experiments proved that the synthesis of malate is not the rate-limiting step for its efflux from roots, although overexpression of a nodule-enhanced form of malate dehydrogenase was also able to considerably enhance the exudation of malate in an Al-sensitive alfalfa cultivar [22]. Recently, an important step toward the understanding of the regulatory mechanisms of malate excretion was made. In a forward genetic screen, the putative $\mathrm{Cys}_{2} \mathrm{His}_{2}$-type zinc finger transcription factor, STOP1 (sensitive to proton rhizotoxicity 1), which is responsible for the strong induction of ALMT1 transcripts after Al treatment, was identified [19,23]. Plants with defects in STOP1 did not show induced expression of ALMT1 and malate release after Al treatment and exhibited an Al-hypersensitive phenotype [23]. Interestingly, Rudrappa et al. [24] uncovered another important role for ALMT1 in root exudation of malate. Arabidopsis seedlings that were infected with the foliar pathogen Pseudomonas syringae exudated malate to recruit the beneficial rhizobacterium Bacillus subtilis in a dose-dependent manner, reducing its susceptibility to pathogen attack.

\section{Future directions}

Besides the already known roles and functions of malate in plant metabolism, there still seems to be more to uncover. The role of malate as a root exudate determining interactions of plant microbia and resistance to acidic soils may have broad impacts on biodiversity and the distribution of plant communities. One interesting issue will be to decipher the signalling pathways that lead to increased exudation of malate into the apoplast and soil, which also seems to involve root-to-shoot communications. The identification of the guard cell-specific malate-sensitive anion channel raises the possibility that similar proteins might be uncovered, which would help us to understand in more detail how malate homeostasis is regulated at the cellular level and may have important roles in signalling.

\section{Abbreviations}

$\mathrm{Al}$, aluminium; ALMT1, aluminium-activated malate transporter 1; SLAC1, slow anion channel-associated 1 protein; STOP1, sensitive to proton rhizotoxicity 1; TCA, tricarboxylic acid.

\section{Competing interests}

The authors declare that they have no competing interests.

\section{Acknowledgements}

We would like to apologize to the colleagues whose work could not be cited due to space restrictions. IF was supported by a Feodor-Lynen fellowship (AvH). 


\section{References}

I. Martinoia E, Rentsch D: Malate compartmentation: responses to a complex metabolism. Annu Rev Plant Physiol Plant Mol Biol 1994, 45:447-67.

2. Schneidereit J, Häusler RE, Fiene G, Kaiser WM, Weber AP: Antisense repression reveals a crucial role of the plastidic 2-oxoglutarate/malate translocator DiTI at the interface between carbon and nitrogen metabolism. Plant J 2006, 45:206-24.

FI000 Factor 3.0 Recommended

Evaluated by Richard Leegood 10 Jan 2006

3. Nunes-Nesi A, Carrari F, Lytovchenko A, Smith AM, Loureiro ME, Ratcliffe RG, Sweetlove LJ, Fernie AR: Enhanced photosynthetic performance and growth as a consequence of decreasing mitochondrial malate dehydrogenase activity in transgenic tomato plants. Plant Physiol 2005, I37:6 I I-22.

FI000 Factor 3.2 Recommended

Evaluated by Richard Leegood 02 Feb 2005, Steven Huber 09 Feb 2005

4. Tcherkez G, Bligny R, Gout E, Mahé A, Hodges M, Cornic G: Respiratory metabolism of illuminated leaves depends on CO2 and 02 conditions. Proc Natl Acad Sci U S A 2008, I 05:797802 .

5. Nunes-Nesi A, Sulpice R, Gibon Y, Fernie AR: The enigmatic contribution of mitochondrial function in photosynthesis. J Exp Bot 2008, 59:1675-84.

6. van der Merwe MJ, Osorio S, Moritz T, Nunes-Nesi A, Fernie AR: Decreased mitochondrial activities of malate dehydrogenase and fumarase in tomato lead to altered root growth and architecture via diverse mechanisms. Plant Physiol 2009, 149:653-69.

7. Schwender J, Shachar-Hill Y, Ohlrogge JB: Mitochondrial metabolism in developing embryos of brassica napus. J Biol Chem 2006, 28I:34040-7.

FI000 Factor 3.0 Recommended Evaluated by Richard Leegood 04 Oct 2006

8. Sweetlove LJ, Fell D, Fernie AR: Getting to grips with the plant metabolic network. Biochem J 2008, 409:27-4I.

9. Hedrich R, Marten I, Lohse G, Dietrich P, Winter H, Lohaus G, Heldt HW: Malate-sensitive anion channels enable guard cells to sense changes in the ambient $\mathbf{C O 2}$ concentration. Plant J 1994, 6:74|-8.

10. Lee M, Choi Y, Burla B, Kim YY, Jeon B, Maeshima M, Yoo JY, Martinoia E, Lee $Y$ : The ABC transporter AtABCB 14 is a malate importer and modulates stomatal response to $\mathrm{CO2}$. Nat Cell Biol 2008, 10:1217-23.

FI000 Factor 6.5 Must Read

Evaluated by Julian Schroeder 03 Oct 2008, Martin Robert McAinsh 24 Oct 2008, Alisdair Fernie 27 Oct 2008

II. Hedrich R, Marten I: Malate-induced feedback regulation of plasma membrane anion channels could provide a $\mathrm{CO} 2$ sensor to guard cells. EMBO J 1993, I 2:897-90I.

12. Negi J, Matsuda O, Nagasawa T, Oba Y, Takahashi H, KawaiYamada $M$, Uchimiya $H$, Hashimoto $M$, lba $K$ : $C O 2$ regulator SLACI and its homologues are essential for anion homeostasis in plant cells. Nature 2008, 452:483-6.

FI000 Factor 6.6 Must Read

Evaluated by Enrico Martinoia 07 Mar 2008, Michael Gjedde Palmgren 12 Mar 2008, Martin Robert McAinsh 03 Apr 2008

13. Vahisalu T, Kollist H, Wang YF, Nishimura N, Chan WY, Valerio G, Lamminmäki A, Brosché M, Moldau H, Desikan R, Schroeder Jl, Kangasjärvi J: SLACI is required for plant guard cell S-type anion channel function in stomatal signalling. Nature 2008, 452:487-9l.

FI000 Factor 8.2 Exceptional

Evaluated by Enrico Martinoia 10 Mar 2008, Michael Gjedde Palmgren 12 Mar 2008, Martin Robert McAinsh 03 Apr 2008

14. Nunes-Nesi A, Carrari F, Gibon Y, Sulpice R, Lytovchenko A, Fisahn J, Graham J, Ratcliffe RG, Sweetlove LJ, Fernie AR: Deficiency of mitochondrial fumarase activity in tomato plants impairs photosynthesis via an effect on stomatal function. Plant / 2007, 50:1093-106

15. Ma JF, Ryan PR, Delhaize E: Aluminium tolerance in plants and the complexing role of organic acids. Trends Plant Sci 200I, 6:273-8.

16. Delhaize E, Ryan PR, Randall PJ: Aluminum tolerance in wheat (Triticum aestivum L.) (II. Aluminum-stimulated excretion of malic acid from root apices). Plant Physiol 1993, 103:695-702.

17. Hoekenga OA, Vision TJ, Shaff JE, Monforte AJ, Lee GP, Howell SH, Kochian LV: Identification and characterization of aluminum tolerance loci in Arabidopsis (Landsberg erecta x Columbia) by quantitative trait locus mapping. A physiologically simple but genetically complex trait. Plant Physiol 2003, I32:936-48.

18. Sasaki T, Yamamoto Y, Ezaki B, Katsuhara M, Ahn SJ, Ryan PR, Delhaize $\mathrm{E}$, Matsumoto $\mathrm{H}$ : A wheat gene encoding an aluminumactivated malate transporter. Plant J 2004, 37:645-53.

19. Hoekenga OA, Maron LG, Piñeros MA, Cançado GM, Shaff J, Kobayashi Y, Ryan PR, Dong B, Delhaize E, Sasaki T, Matsumoto H, Yamamoto Y, Koyama H, Kochian LV: AtALMTI, which encodes a malate transporter, is identified as one of several genes critical for aluminum tolerance in Arabidopsis. Proc Natl Acad Sci U S A 2006, 103:9738-43.

FI000 Factor 3.0 Recommended

Evaluated by Nicolaus Von Wiren 24 Aug 2006

20. Piñeros MA, Cançado GM, Kochian LV: Novel properties of the wheat aluminum tolerance organic acid transporter (TaALMTI) revealed by electrophysiological characterization in Xenopus oocytes: functional and structural implications. Plant Physiol 2008, I47:2 I31-46.

21. Delhaize E, Ryan PR, Hebb DM, Yamamoto Y, Sasaki T, Matsumoto H: Engineering high-level aluminum tolerance in barley with the ALMTI gene. Proc Natl Acad Sci U S A 2004, I 0 I:I5249-54.

FI000 Factor 3.0 Recommended

Evaluated by Lee Sweetlove 30 Nov 2004

22. Tesfaye M, Temple SJ, Allan DL, Vance CP, Samac DA: Overexpression of malate dehydrogenase in transgenic alfalfa enhances organic acid synthesis and confers tolerance to aluminum. Plant Physiol 2001, I 27:1836-44.

FI000 Factor 6.0 Must Read

Evaluated by Enrico Martinoia 18 Jan 2002

23. luchi S, Koyama H, luchi A, Kobayashi Y, Kitabayashi S, Kobayashi Y, Ikka T, Hirayama T, Shinozaki K, Kobayashi M: Zinc finger protein STOPI is critical for proton tolerance in Arabidopsis and coregulates a key gene in aluminum tolerance. Proc Natl Acad Sci U S A 2007, 104:9900-5.

FI000 Factor 3.0 Recommended

Evaluated by Julian Schroeder OI Aug 2007

24. Rudrappa T, Czymmek KJ, Paré PW, Bais HP: Root-secreted malic acid recruits beneficial soil bacteria. Plant Physiol 2008, I 48: | 547-56.

FI000 Factor 6.5 Must Read

Evaluated by Maurice Sabelis 19 Feb 2009, Venkatesan Sundaresan 10 Nov 2008, Ben Lugtenberg 03 Dec 2008 